\title{
An integrative approach to clinical recovery for COVID- 19 patients using an Ayurvedic formulation: $A$ multicentric double-blind randomized control trial.
}

\section{Pankaj Bhardwaja}

AllMS Jodhpur

Kalaiselvan Ganapathy

Sri Manakula Vinayagar Medical College and Hospital

Monika Pathania

AlIMS Rishikesh

K H Naveen

AllMS Jodhpur

Jaykaran Charan

AllMS Jodhpur

Siddhartha Dutta

AlIMS Jodhpur

Ravisekhar Gadepalli

AllMS Jodhpur

Srikanth Srinivasan

AllMS Jodhpur

Manoj Kumar Gupta

AllMS Jodhpur

Akhil D Goelj

AllMS Jodhpur

Naresh Midha

AllMS Jodhpur

Bharat Kumar

AllMS Jodhpur

Meenakshi Sharma

AlIMS Jodhpur

Praveen Sharma

AllMS Jodhpur

Mithu Banerjee

AllMS Jodhpur

Prasenjit Mitra

AllMS Jodhpur

\section{Sanjeev Misra}


AllMS Jodhpur

\section{Vinayagamoorthy $\mathrm{V}$.}

Sri Manakula Vinayagar Medical College and Hospital

\section{Girija Subramaniant}

Sri Manakula Vinayagar Medical College and Hospital

\section{Praveen $\mathbf{R}$}

Sri Manakula Vinayagar Medical College and Hospital

\section{Minakshi Dhar}

AlIMS Rishikesh

\section{Vartika Saxena}

AllMS Rishikesh

\section{Puneet Dhamija}

AllMS Rishikeh

\section{Archana Singh}

AlIMS Rishikesh

\section{Saumya Subramanian}

SRI SRI INSTITUTE FOR ADVANCED RESEARCH

Divya Kanchibhotlaz ( $\sim$ divya.kanchibhotla@artofliving.org )

SRI SRI INSTITUTE FOR ADVANCED RESEARCH

\section{Research Article}

Keywords: Ayurveda, COVID-19, RT-PCR, Early Recovery, NOQ19

Posted Date: December 27th, 2021

DOI: https://doi.org/10.21203/rs.3.rs-1165680/v1

License: (c) (1) This work is licensed under a Creative Commons Attribution 4.0 International License. Read Full License 


\section{Abstract}

\section{Background}

Traditional medicine systems such as Ayurveda contain a vast repository of naturally occurring herbs with strong antimicrobial potency. A multitude of complementary therapies have been explored for their therapeutic role to treat COVID-19 during the pandemic. There have been promising results reported from in silico, in vitro and in vivo studies that need to be further explored in humans.

\section{Objective}

The present randomized placebo control trial evaluates the clinical efficacy of an integrated approach including Ayurvedic polyherbal formulation, NOQ19 in the improvement of mild to moderate category of COVID-19 infected patients.

\section{Patients and methods}

A multicentric, randomized, placebo control design was adopted for the study. A total of 76 patients with positive COVID-19 RT-PCR test were enrolled in the study; 39 in the NOQ19 arm and 37 in the placebo arm. Patients were randomized and blinded to their respective intervention, which was provided along with the standard of care treatment. Rate of recovery assessment was done on Day 3, 5 and 7 via RT-PCR test to measure the rate of recovery. Blood markers were analysed on Day 0 and Day 7.

\section{Outcomes}

The patients were assessed for rate of recovery via RT-PCR and improvement in blood biomarkers. They were also monitored for any adverse events or side effects of the drug.

\section{Results}

The present study demonstrated a significant early recovery in the patients who took the NOQ19 formulation. Patients who received NOQ19 with the standard care of treatment showed clinical improvement in terms of oxygen requirement, breathlessness and $\mathrm{SpO} 2$, though the difference was not statistically significant. Moreover, no side effects were observed with the use of NOQ19.

\section{Conclusion}

An overall integrated approach of standard of care treatment with Ayurvedic formulation (NOQ19) results in early clinical outcome in the management of mild to moderate cases of COVID-19.

\section{Introduction}

The COVID-19 pandemic has created an unprecedented wave of illness and loss of life compared to any other outbreak in the past few decades. Health care professionals, pharmaceutical industry and scientists from various countries have been investigating pre- existing and novel compounds as potential solutions to end this pandemic ${ }^{1}$. One of the major milestones to protect the population from the SARS-CoV-2 virus, was the 
development of safe and efficacious COVID-19 vaccines. To date, 6.34 billion vaccines have been administered globally. Almost half of the world population (45.7\%) has received at least one dose and 2.68 billion are fully vaccinated ${ }^{2}$.

Traditional Indian systems of medicine like Ayurveda and Siddha have also emerged with pragmatic solutions during the COVID-19 outbreak. A review of the literature suggests many single drugs or compound formulations emanating from Ayurveda can boost immunity and provide antiviral activity against SARS-CoV$2^{3-7}$. Preclinical studies also provide robust evidence of antiviral potency of various phytochemicals present in nature. In silico studies of well-known immuno-boosters like Ashwagandha (Withania somnifera), Guduchi (Tinospora cordifolia) and Tulsi (Ocimum sanctum) show strong docking properties against SARS-CoV-2 viral proteins $^{8}$. The phytoconstituents of Ashwagandha (Withania somnifera), Withanoside V showed a binding energy of $-8.96 \mathrm{Kcal} / \mathrm{mol}$ with the $\mathrm{M}^{\text {pro }}$ protein of the virus ${ }^{9}$. A randomized clinical trial on Ashwagandha (Withania somnifera) demonstrated an improvement in markers of vaccine response, such as IgG titer, when Ashwagandha was given along with vaccine, in comparison to receiving vaccine alone ${ }^{10}$.

Similarly, compound sesline from Bilwa (Aegle marmelos) and several other compounds from Guduci (Tinospora cordifolia) and Tulsi (Ocimum sanctum) may serve as a potential inhibitor against the Mpro protein of SARS-CoV-2 virus, as shown in in-silico studies ${ }^{8,11-12}$. Other in- silico studies demonstrate that phytochemicals present in herbs used regularly as a part of Indian diet, like Bilwa (Aegle marmelos), Khus (Vetiveria zizanioides), Drumstick (Moringa Oleifera), and Pomegranate (Punica granatum) exhibit significant binding with RdRp and Mpro proteins of SARS-CoV-2 virus ${ }^{13}$. Components of Yashtimadhu (Glycyrrhiza glabra), another well-known Ayurvedic herb, were noticed to have significant binding affinity with various SARS-CoV-2 proteins (main protease, spike protein and RdRp protein) and host macromolecular targets such as human (ACE2 and furin) proteins ${ }^{14}$. Vasaka (Adhatoda vasica), another potent Ayurvedic compound, exhibited a strong binding energy with Mpro of SARS-CoV-2 $(-114.9 \mathrm{kcal} / \mathrm{mol})^{15}$. In vivo studies among animal models showed that ayurvedic nasal formations limited the viral entry and replication ${ }^{16}$. These are just a few ayurvedic herbs and compounds that have shown antiviral properties against SARS-CoV-2 and can be used in the management of COVID-19.

A novel polyherbal Ayurvedic formulation called NOQ19 containing 19 ingredients from 13 herbs has shown efficacy against the SARS-CoV-2 in in vitro and in vivo studies. NOQ19 contains several potent antivirals and immunomodulators including Ashwagandga (Withania somnifera), Tulasi (Ocimum sanctum), Guduchi (Tinospora cordifolia), Bilwa (Aegle marmelos), Vasaka (Adhatoda vasica) and Yasthimadhu (Glycyrrhiza glabra). Other components such as Bhumiamla (Phyllanthus fraternus), Bhunimba (Andrographis paniculata) and Haridra (Curcuma longa) are also used in the formulation.

Bhunimba (Andrographis paniculata), a well-known Ayurvedic herb, is used to treat viral and microbial infections ${ }^{17}$. An in-vitro study of Bhunimba (Andrographis paniculata) and Chiretta (Andrographolide) in SARS-CoV-2-infected Calu-3 cell lines (infected human lung epithelial cells) showed that these herbs significantly inhibit the production of infectious virions with an IC50 of $0.036 \mu \mathrm{g} / \mathrm{mL}$ and $0.034 \mu \mathrm{M}$, respectively ${ }^{18}$. One of the other mentioned uses of Bhunimba (Andrographis paniculata) is its antithrombotic effect. There is evidence of thrombotic pathways being implicated in COVID-19 with ample instances of 
thrombotic events leading to mortality in patients ${ }^{19}$. Due to its antithrombotic activity, Bhunimba (Andrographis paniculata) can play a significant role in the management of patients with COVID-19. The crude extracts of Bhunimba (Andrographis paniculata) also demonstrate an antithrombotic property in-vitro ${ }^{20}$. Haridra (Curcuma longa), another constituent of NOQ19, has excellent anti-inflammatory properties and thereby can regulate the cytokine release during the COVID-19 infection. Curcumin present in Haridra, regulates the Toll-like receptors, inflammatory cytokines and chemokines, which play a major role in pathophysiology and progression of the disease. Due to its phenolic nature, it also has an intensive antimicrobial effect ${ }^{21,22}$.

A previous in vitro study conducted on NOQ19 demonstrated its antiviral efficacy among Vero E6 SARS-CoV-2 infected cell lines. The treatment of virus infected cells with $0.9 \mathrm{mg} / \mathrm{ml}$ concentration of NOQ19 resulted in a $100 \%$ viral elimination ${ }^{23}$. The NOQ19 was further tested in the Syrian golden hamsters animal model. A 78.2\% viral load reduction in hamsters lungs was observed with NOQ19. No toxicity was reported in the animal mode ${ }^{24}$. With the preclinical efficacy established, the drug was further tested in an open label feasibility study. The study showed a 74\% rate of recovery among the COVID-19 patients after 5 days of NOQ19 consumption ${ }^{25}$.

To evaluate further effectiveness and therapeutic role of NOQ19, this multicentric study was conducted with the hypothesis that NOQ19 will contribute towards early recovery of patients in mild-moderate SARS-CoV-2 infection.

\section{Material And Methods}

\subsection{Trial design}

A multicentric, double blind randomized control design was adopted for this study. The study was coordinated at the All India Institute for Medical Sciences (AIIMS), Jodhpur. The patients were enrolled from three locations namely All India Institute for Medical Sciences, Jodhpur ; All India Institute for Medical Sciences, Rishikesh and Sri Manakula Vinayagar Medical College and Hospital (SMVMCH), Puducherry. The study was approved by Institutional Ethics Committee of all 3 sites, with study registration numbers for individual sites as: AllMS Jodhpur AlIMS/IEC/2021/3626; AllMS Rishikesh AlIMS/IEC/21/306 and SMVMCH, Puducherry SMVMCHECO-AL/153/2021. The study was registered at Clinical Trial Registry, India bearing registration number CTRI/2021/05/033790. The protocol of the study was standardized and finalized at the All India Institute for Medical Sciences, Jodhpur and was in compliance with Helsinki ethical standards and Good Clinical Practice. The data was collected across the sites from June 7th to August 28th, 2021. Each patient was monitored for 7 days or until they turned RT-PCR negative.

\subsection{Participants}

A total of 76 participants, from the In-patient ward (IPD) or the Out-patient clinic (OPD) at the three study locations, were enrolled in the study. The patients who presented with COVID-19 symptoms and had a positive RT-PCR test were briefed about the study by research fellows in the presence of the doctor on duty, at all three locations. Based on their medical history, patients who met the eligibility criteria, mentioned below, were invited to participate in the study and informed consent was obtained. 


\subsubsection{Inclusion Criteria}

- Age group: 18-75 years

- A positive RT-PCR test for COVID-19

- Symptomatic, Mild-Moderate patients as defined by Government of India26 with or without comorbidities.

- Patients presenting to the hospital within 3 days of onset of symptoms

- Patients willing to take Ayurvedic medicine

\subsubsection{Exclusion Criteria}

- Patients with severe illness such as AIDS, chronic diabetes, chronic heart condition

- Pregnant or lactating mothers

- Patients severely infected by COVID-19, either on ventilation or in ICU.

\subsection{Intervention}

All the patients were provided a bottle of intervention drug or placebo based on the computer generated sequence of randomization. Each bottle contained 90 tablets. The patients were advised to take 2 tablets, under supervision, thrice a day for 14 days, after food. Both the placebo and N0Q19 bottles were packaged identically to avoid bias. Compliance was monitored by the data collector individually over the phone for OPD patients and in person for IPD patients.

\subsubsection{NOQ19 preparation}

NOQ19 is a 19 ingredient polyherbal formulation, containing 13 potent antiviral and anti- inflammatory compounds such as Ashwagandha (Withania somnifera) powder and extract, Yashtimadhu (Glycyrrhiza glabra) powder and extract, Vasaka (Adhatoda vasica) powder and extract, Bilwa (Aegle marmelos), Rasna (Pluchea lanceolata), Pippali (Piper longum), Haridra (Curcuma longa), Patha (Cissampelos pareira), Bhumiamla (Phyllanthus fraternus) powder and extract, Saptaparna (Alstonia scholaris), Tulasi (Ocimum sanctum), Bhunimba (Andrographis paniculata) powder and extract, and Guduci (Tinospora cordifolia) powder and extract. The drug was produced by Sriveda Sattva Pvt Ltd, Bangalore (Sri Sri Tattva), a GMP certified company. It was licensed by the Ministry of AYUSH, Govt. of India (License number- AUS782). The crude forms of all the herbal extracts were subjected to quality control. Thereafter, the ingredients were blended with excipients followed by granulation, drying and compression. After QC analysis, the tablets were packed using the standard procedure.

\subsubsection{Comparator group}

The comparator group in this trial were given a placebo tablet. The placebo tablet was made of starch (100\%). The placebo tablets were also tested for quality control and packed in bottles identical to NOQ19.

\subsubsection{Standard of care treatment}


The standard of care treatment was administered as per the guidelines provided by the Ministry of Health and Family welfare, Government of India, during the second wave COVID-1927. However, the drugs were slightly different at each study location. The standard of care treatment at each location is described below:

\subsubsection{AllMS Jodhpur:}

All the patients enrolled in the study from AlIMS Jodhpur were classified as moderate COVID-19 cases. They were given the following standard of care treatment: Inj. Remdesivir (100mg OD 5 days), Inj. Dexona (6 mg IV (steroid) OD 5 days, Given only in patients who were on oxygen), Inj LMWHeparin (0.6ml OD 10 days), Tablet Augmentin (625 mg TDS), Tablet Azithromycin (500 mg, One Tablet, OD 5 days), Tablet Limcee (500 mg T.D.S, 10 days).

\subsubsection{SMVMCH Puducherry and AllMS Rishikesh:}

Patients in SMVMCH Puducherry and AIIMS Rishikesh included both mild and moderate patients and were administered the following standard of care treatment.

\subsection{Mild Patients:}

OPD patients with mild disease were prescribed Tablet Azithromycin ( $500 \mathrm{mg}$, one tablet, OD 5 days), Vitamin C (one tablet, BD 7 days), Zinc (one tablet, OD 7 days), Tablet Ivermectin (12 mg OD 3 days), Cap. Doxycycline (100 mg, BD 5 days), Tablet Rivaroxaban (15mg, OD 15 days)

\subsection{Moderate Patients:}

Moderate patients admitted to the hospital were given Inj. Remdesivir (200 mg IV on day 1 followed by $100 \mathrm{mg}$ IV for 4 days), steroids Inj. Methyl Prednisolone or Inj. Dexamethasone, Inj Enxoparin 40 Mg, Doxycycline (100mg, BD for 5 days), Azithromycin (500mg, one tablet, OD, for 5 days), and Supportive therapy of Zinc, Vitamin $\mathrm{C}$ and Fluids.

\subsection{Outcomes}

\subsubsection{Primary Outcome:}

The Primary Outcome measured was the rate of recovery among patients in NOQ19 and Placebo arms, using the RT-PCR negative test. One nasal swab and one throat swab was collected and subjected to analysis for viral load reduction at Day 3, 5 and 7.

\subsubsection{Secondary Outcomes:}

The secondary outcomes included assessment of clinical markers and blood biomarkers, both of which served as an indication of clinical improvement post intervention. The clinical markers of significance for $\mathrm{C}$ OVID-19 infected patients, especially moderate patients, measured in this study included fever, dyspnoea (breathlessness), SpO2 levels and need for oxygen support. Blood biomarkers included levels of total lymphocyte count, IL-6 (cytokine marker) and CRP (inflammatory marker). The study also recorded any adverse events or side effects from the drug.

\subsubsection{Follow up and Assessment:}


The RT-PCR tests were conducted on Day 0, Day 3, Day 5 and Day 7. Blood biomarkers were tested on Day 0 and Day 7. Other clinical markers were assessed on Day 0, Day 3, Day 5 and Day 7. Patients were monitored for a maximum of 7 days, or until RT-PCR negative result, whichever was earlier. Information about any adverse events reported by the patients following the intervention was also collected.

\subsection{Sample calculation}

Based on the sample size formula ${ }^{28}$, a sample size of 380 was calculated for the overall study.

\section{$\underline{N=z 2^{*} p(1-p)}$}

E2

$\mathbf{z}$ is the $\mathbf{z}$ score

$\boldsymbol{\varepsilon}$ is the margin of error

$\mathbf{N}$ is the population size

$\mathbf{p}$ is the population proportion

$$
=\frac{1.966^{*} 0.5(1-0.5)}{0.05^{2}}=385
$$

However, due to the decrease in the cases of COVID-19, a total of 76 patients with positive COVID-19 infection were enrolled, 39 in the NOQ19 arm and 37 in the placebo arm and the data is presented as an interim report.

\subsection{Randomization and blinding}

A computer-generated sequence of randomization was adopted for the study. Based on the inflow of patients at each study site, the participants were randomized to the two study groups in a 1:1 ratio. The randomization was conducted by a research associate who was not involved in the study. The patients were assigned the respective intervention by a nurse who was not a part of the study. Along with the patients, the lab technician, data collector, data operator and statistician were blinded to the randomization group.

\subsection{Statistical analysis}

An Intention to Treat (ITT) approach was utilized for data analysis. The patient data was pooled from the three sites. The baseline characteristics were reported as proportion/ mean (SD) for both the study groups.

Compilation and analysis of the data was performed in Microsoft Excel 2019 (16.0.12026.20334) 32-bit. Data was tested for normality using the IBM SPSS statistics software version 2.0. The blood parameters were evaluated by descriptive statistics. Association between variables of qualitative nature was tested by Student's T Test (paired and unpaired) wherever appropriate at significance of 5\%. Quantitative data not normally distributed in nature was analyzed using Mann-Whitney Test (for two groups) and Independent t test was used for comparison of normally distributed data between two groups at a 95\% confidence interval.

\subsubsection{Sub-group analysis}


The data was further separated into mild and moderate patients based on Government of India guidelines ${ }^{26}$. The categorization as per the guidelines was on SpO2 levels or respiratory rate. The clinical improvement in moderate patients was further evaluated.

\section{Results}

The present study evaluates the rate of recovery and clinical improvement in SARS-CoV-2 infected patients following an Ayurvedic intervention called NOQ19. The study enrolled a total of 76 patients. Patients who turned RT-PCR negative before day 7 were not considered as drop outs.

A comparison of demographic characteristics demonstrated similarities in both study arms, across the three sites (Table1). No significant variation was noticed in the age, height, weight, or severity of illness of the study population at the time of enrollment. Clinical parameters such as temperature, respiration rate, SpO2 and pulse rate of recruited subjects were also collected. Majority of the patients in the study were diagnosed with mild infection, and a few as moderate.

Table 1

Participants Characteristics at Baseline $(\mathrm{N}=76)$

\begin{tabular}{|c|c|c|c|c|}
\hline Demography & Type & NOQ19(n=39) & Placebo(n=37) & p Value \\
\hline \multirow[t]{2}{*}{ Gender n(\%) } & Male & $17(43.6)$ & $25(65.8)$ & $N A$ \\
\hline & Female & $22(56.4)$ & 13(34.2) & \\
\hline \multirow[t]{4}{*}{ Age Mean(SD) } & & $44(13)$ & $44(14)$ & \multirow[t]{4}{*}{0.92} \\
\hline & Median & 45 & 46 & \\
\hline & Max & 65 & 65 & \\
\hline & Min & 21 & 18 & \\
\hline Weight Mean(SD) & & $66(12)$ & $67(10)$ & 0.64 \\
\hline Height Mean(SD) & & 159(9) & $161(8)$ & 0.20 \\
\hline \multirow[t]{2}{*}{ Severity $n(\%)$} & Mild & $33(84.6)$ & $34(89.5)$ & \multirow[t]{2}{*}{0.74} \\
\hline & Moderate & $6(15.4)$ & $4(10.5)$ & \\
\hline Temperature Mean(SD) & & $92(17)$ & $93(17)$ & 0.90 \\
\hline Respiration Rate (per min) & & $17(2.4)$ & $17(2.3)$ & 0.76 \\
\hline \multicolumn{5}{|l|}{ Mean(SD) } \\
\hline Sp02 & & $96.8(1.6)$ & $97.2(2.05)$ & 0.39 \\
\hline \multicolumn{5}{|l|}{ Mean(SD) } \\
\hline Pulse Rate (per min) Mean(SD) & & $86.7(9.8)$ & 87.3(8.7) & 0.76 \\
\hline
\end{tabular}


Follow up analysis of the patients' rate of recovery post intervention is captured in Table 2. The RT-PCR analysis of patients in the NOQ19 arm on day 3 showed a higher percentage of recovered population (44\%), compared to the placebo arm (34\%). The trend continued on day 5 and day 7 , with a slightly higher percentage of population recovering in the NOQ19 arm compared to the Placebo arm. However, the subgroup analysis of patients with moderate infection (requiring hospitalization), demonstrated a significant rate of recovery at Day 3 in the NOQ19 arm. 75\% of the patients recovered at day 3 itself in the NOQ19 arm, while a slow and gradual improvement in the placebo arm was noticed over the course of the week.

Table 2

Percentage rate of recovery among NOQ19 arm and Placebo arm as measured by RT-PCR negative population

\begin{tabular}{|c|c|c|c|}
\hline \multicolumn{4}{|c|}{ RT-PCR Negative \% (Total Population) } \\
\hline RT-PCR & NOQ19 (n=39) n (\%) & Placebo $(n=37) n(\%)$ & Intergroup p value \\
\hline \multicolumn{4}{|l|}{ Negative } \\
\hline Day 0 & $0(0 \%)$ & $0(0 \%)$ & \\
\hline Day3 & $15(44.1 \%)$ & $11(34.4 \%)$ & 0.46 \\
\hline Intragroup $p$ value Day0 vs. 3 & $<0.001^{\star *}$ & $<0.001^{* *}$ & \\
\hline Day 5 & $20(60.6 \%)$ & $18(60 \%)$ & 1 \\
\hline Intragroup $p$ value Day0 vs. 5 & $<0.001^{* *}$ & $<0.001^{* *}$ & \\
\hline Day 7 & $27(79.4 \%)$ & $22(73.3 \%)$ & 0.77 \\
\hline Intragroup $p$ value Day0 vs. 7 & $<0.001^{\star \star}$ & $<0.001^{\star *}$ & \\
\hline \multicolumn{4}{|c|}{ RT-PCR Negative \% (Moderate Population) } \\
\hline RT-PCR & NOQ19 $(n=6)$ & Placebo $(n=4)$ & Intergroup p value \\
\hline \multicolumn{4}{|l|}{ Negative } \\
\hline Day 0 & $0(0 \%)$ & $0(0 \%)$ & \\
\hline Day3 & $3(75 \%)$ & $1(25 \%)$ & 0.13 \\
\hline Intragroup $p$ value Day0 vs. 3 & $0.04^{*}$ & 0.39 & \\
\hline Day 5 & $3(75 \%)$ & $2(50 \%)$ & 0.42 \\
\hline Intragroup p value Day0 vs. 3 & $0.04^{*}$ & 0.18 & \\
\hline Day 7 & $3(75 \%)$ & $3(75 \%)$ & 0.88 \\
\hline Intragroup $p$ value Day0 vs. 3 & $0.04^{*}$ & 0.057 & \\
\hline \multicolumn{4}{|l|}{ * $p$ value $<0.05$ - significant } \\
\hline$\star \star ~ p$ value $<0.001$ - very signific & & & \\
\hline
\end{tabular}


Patients in the NOQ19 arm showed a faster improvement in clinical parameters (Table 3). It was observed that the SpO2 levels improved significantly among the patients in the NOQ19 arm by day 3. Further follow up evaluations at day 5 and day 7 also demonstrated significant improvements in the SpO2 levels. An intra group comparison demonstrated that SpO2 levels in the placebo arm remained almost constant throughout the study time points. A similar significant improvement was found in the number of patients with breathlessness, which decreased significantly in the NOQ19 arm (30.7-15.4\% to $0 \%)$. The percentage of the population experiencing breathlessness was lesser in the placebo arm at baseline, and the placebo arm showed a gradual improvement in breathlessness, slower than the NOQ19 arm. A correlating trend was also observed in the percentage of people requiring oxygen between both arms. The percentage of patients requiring oxygen rapidly decreased in the NOQ19 arm and none of the patients required oxygen support by day 7, however, the number of patients requiring oxygen support in the placebo arm remained constant throughout the time points. Although both arms experienced an improvement in the blood biomarkers, no significant changes were noted in IL6, CRP or TLC values between the two study groups at day 0 or day 7. None of the patients in the NOQ19 arm reported any adverse event, allergies or discomfort after taking NOQ19 daily. 
Table 3

Clinical Parameters of Significance among patients admitted in hospital

\begin{tabular}{|c|c|c|c|c|}
\hline Parameters & Time point & $\begin{array}{l}\text { NOQ19 Arm } \\
(n=39)\end{array}$ & $\begin{array}{l}\text { Placebo Arm } \\
(n=37)\end{array}$ & $\begin{array}{l}\text { Inter group p } \\
\text { value }\end{array}$ \\
\hline \multirow{10}{*}{$\begin{array}{l}\text { Absence of } \\
\text { Fever }\end{array}$} & \multirow[t]{2}{*}{ Day 0} & 17 & \multirow[t]{2}{*}{$13(36.11 \%)$} & \multirow[t]{2}{*}{0.486} \\
\hline & & $(44.74 \%)$ & & \\
\hline & \multirow[t]{2}{*}{ Day 3} & 29 & \multirow[t]{2}{*}{$28(93.33 \%)$} & \multirow[t]{2}{*}{1.000} \\
\hline & & $(90.63 \%)$ & & \\
\hline & $\begin{array}{l}p \text { value day } 0 \\
\text { vs. } 3\end{array}$ & $0.0001^{* *}$ & $0.001^{* *}$ & \\
\hline & Day 5 & $28(72 \%)$ & 28 (75.7\%) & 1.000 \\
\hline & $\begin{array}{l}p \text { value day } 0 \\
\text { vs. } 5\end{array}$ & $<0.001^{* *}$ & $<0.001^{\star *}$ & \\
\hline & Day 7 & 26 & $25(67.65 \%)$ & 1.000 \\
\hline & & $(66.7 \%)$ & & \\
\hline & $\begin{array}{l}p \text { value day } 0 \\
\text { vs. } 7\end{array}$ & $<0.001^{\star *}$ & $<0.001^{* *}$ & \\
\hline \multirow[t]{7}{*}{ Sp02 (mean) } & Day 0 & 96.8 & 97.2 & 0.356 \\
\hline & Day 3 & 97.7 & 97.3 & 0.481 \\
\hline & $\begin{array}{l}\text { p value day } 0 \\
\text { vs. } 3\end{array}$ & 0.043 & 0.284 & \\
\hline & Day 5 & 97.8 & 97.7 & 0.845 \\
\hline & $\begin{array}{l}p \text { value day } 0 \\
\text { vs. } 5\end{array}$ & $0.008^{*}$ & 0.252 & \\
\hline & Day 7 & 97.9 & 97.6 & 0.442 \\
\hline & $\begin{array}{l}p \text { value day } 0 \\
\text { vs. } 7\end{array}$ & $0.002^{*}$ & 0.362 & \\
\hline \multirow{6}{*}{$\begin{array}{l}\text { Percentage of people with } \\
\text { Breathlessness }\end{array}$} & Day 0 & $12(30.7 \%)$ & $6(16.2 \%)$ & 0.182 \\
\hline & Day 3 & $6(15.4 \%)$ & $5(13.5 \%)$ & 1.000 \\
\hline & $\begin{array}{l}p \text { value day } 0 \\
\text { Vs. } 3\end{array}$ & 0.221 & 1 & \\
\hline & Day 5 & $6(15.4 \%)$ & $5(13.5 \%)$ & 1.000 \\
\hline & $\begin{array}{l}\text { p value day } 0 \\
\text { vs. } 5\end{array}$ & $0.005^{*}$ & 1 & \\
\hline & Day 7 & $0(0)$ & 2 (5.4\%) & 0.236 \\
\hline
\end{tabular}




\begin{tabular}{|c|c|c|c|c|}
\hline Parameters & Time point & $\begin{array}{l}\text { NOQ19 Arm } \\
(n=39)\end{array}$ & $\begin{array}{l}\text { Placebo Arm } \\
(n=37)\end{array}$ & $\begin{array}{l}\text { Inter group p } \\
\text { value }\end{array}$ \\
\hline & $\begin{array}{l}p \text { value day } 0 \\
\text { vs. } 7\end{array}$ & $0.002^{*}$ & 0.450 & \\
\hline \multirow[t]{5}{*}{ Percentage of people on oxygen } & Day 0 & $5(12 \%)$ & $4(10.8 \%)$ & 1.000 \\
\hline & Day 3 & $3(7.7 \%)$ & $4(10.8 \%)$ & 1.000 \\
\hline & $\begin{array}{l}p \text { value day } 0 \\
\text { vs. } 3\end{array}$ & 0.721 & 1.000 & \\
\hline & Day 5 & 0 & $4(10.8 \%)$ & \\
\hline & $\begin{array}{l}\text { p value day } 0 \\
\text { vs. } 5\end{array}$ & $N A$ & 0.707 & \\
\hline Patients remaining in hospital & Day 7 & 2 & 3 & 0.999 \\
\hline
\end{tabular}

\section{Discussion}

Ayurveda, an ancient Indian system of medicine contains a vast repository of plants and herbs with therapeutic properties. In the fight against COVID-19, herbal extracts with robust scientific evidence of therapeutic efficacy against SARS-CoV-2 can support rapid recovery and reduce mortality due to COVID-19. Our study investigates the effectiveness of NOQ19, an Ayurvedic polyherbal formulation, in clinical improvement and rate of recovery from the SARS-CoV-2 infection. This multicentric trial demonstrates an early recovery among patients who took NOQ19 along with standard of care treatment, compared to those who received standard of care alone.

The study was conducted during the second wave of COVID-19 in India. Along with other upper respiratory symptoms, the chief complain presented by patients during the second wave was shortness of breath associated with low SpO2 levels, requiring oxygen support ${ }^{27,29}$. In our study, a significant clinical improvement was noted in patients among the NOQ19 arm who had experienced lower oxygen saturation and breathlessness at baseline. Patients who received NOQ19 with the standard of care treatment showed an improvement in terms of oxygen requirement, breathlessness and SpO2. Thus, despite lack of intergroup statistical significance, the clinical significance of these findings cannot be ignored.

The second wave of COVID-19 in India was twice as severe as the first wave and created immense pressure on the health infrastructure and economy of the country ${ }^{30}$. Of the total deaths reported in India, $59 \%$ deaths were reported during the second wave ${ }^{31}$.The study was conducted in a hospital, where as per current guidelines, only patients with significant symptoms or considerable comorbidities were included. In the current study, an early clinical recovery was observed among moderate patients. With improvement in oxygen levels and clinical markers, it was noted that patients in the NOQ19 arm were feeling much better than the placebo arm. Also, a lesser number of patients in the NOQ19 arm required hospitalization on day 7. Therefore, this ayurvedic drug can aid early discharge, allowing rational utilization of limited resources, reduced burden on the healthcare system and support management of the illness at home. 
Previous studies on the same formulation NOQ19 have shown promising results with respect to rate of recovery and antiviral efficacy ${ }^{23-25}$. A review of Ayurvedic literature presents robust preclinical evidence for efficacy of multiple NOQ19 ingredients such as Ashwagandha (Withania somnifera) and Guduchi (Tinospora cordifolia), along with Amalaki (Phyllanthus emblica) in proliferation of B and T cells and activation of nonspecific immunity ${ }^{32}$. In addition, several other components of NOQ19 have been highlighted for their antiviral properties previously $8,33,34$. Yashtimadhu (Glycyrrhiza glabra) contains glycyrrhizin, a strong antiviral compound. In a previous study, treatment with different concentrations of glycyrrhizin lowered SARS-CoV viral antigen in a cell culture. At a concentration of $4000 \mathrm{mg} / \mathrm{ml}$, Glycyrrhizin completely blocked the viral replication ${ }^{35}$.

A key observation of our study was the improvement in oxygen levels and reduction in breathlessness among patients with COVID-19, when treated with NOQ19. An earlier study demonstrated the therapeutic efficacy of Vasaka (Adhatoda vasica), present in NOQ19, in an in vitro and in vivo model, via inhibiting the hypoxic response in both the models. A possible mechanism for this could be the reversal of mitochondrial dysfunction associated with hypoxic conditions like asthma, ARDS, etc. ${ }^{36}$. Presence of Vasaka (Adhatoda Vasica) in NOQ19 may be responsible for its antihypoxic effect on COVID-19 patients ${ }^{37}$. Guduchi (Tinospora cordifolia), also present in NOQ19, is another important component studied for improvement in breathlessness ${ }^{38}$. Another clinical trial on patients with COVID-19 showed early recovery and reduced length of hospital stay with an Ayurvedic regime consisting of Dasamoolkaduthrayam Kashaya and Guluchyadi $K_{\text {watham }}{ }^{39}$. A similar observation was noted in our study. Further investigation of the above two rasayanas showed the presence of Bilwa (Aegle marmelos), Pippali (Piper longum), Vaska (Adhatoda vasica) and Guduchi (Tinospora cordifolia) which are also present in NOQ19. AYUSH-64, is a long researched drug for Malaria $^{40}$. During the pandemic, the drug was also tested against SARS-CoV-2 proteins, in silico, and showed excellent binding properties against SARS-CoV-2 virus ${ }^{41}$. Patients who received AYUSH-64 along with standard of care treatment demonstrated a reduced period of hospitalization compared to those who received standard of care treatment alone ${ }^{42}$.

According to data collected by the Ministry of AYUSH via AYUSH Sanjivani App, $80 \%$ of Indians used traditional medicines and home based remedies for the management of COVID-1943. Shortage of hospital beds, paucity of clinical drugs, expensive treatments and the emergence of secondary infections created challenges for patients and healthcare professionals across India during the second wave. Given the large percentage of Indians who rely on traditional remedies, administering an Ayurvedic formulation like NOQ19 along with standard of care can increase adoption and provide a sustainable and effective option to overcome COVID-19 infection safely and quickly. This may also be relevant in societies where people are open towards therapeutic options from traditional systems of medicine.

The authors acknowledge the limitations of the study and present further scope to improve the limitations. One of the key limitations of the study was the small sample size. Due to the small sample size, several clinically significant findings were not statistically significant. Secondly, although the blood biomarkers were captured, eg. IL-6 and D-dimer, no significant difference was noticed among both the groups. A possible reason for this could be that the duration between the two measurements was not long enough to notice any significant difference. Further studies with larger sample size and relatively longer duration can investigate in 
depth efficacy and mechanism of action of NOQ19 in patients with COVID-19. The findings of this study create an interesting backdrop for exploring the role of the NOQ19 in moderate to severe COVID-19 patients on oxygen therapy.

\section{Conclusion}

Traditional and complementary formulations can lend a powerful helping hand to the medical sector in the therapeutic management of COVID-19. The proposed polyherbal formulation, NOQ19, composed of wellknown Ayurvedic herbs demonstrated a significant early recovery in patients with COVID-19. A noted critical symptom during the second wave was lower oxygen saturation levels and breathlessness among patients, which resolved to a greater extent in the NOQ19 group than the placebo group, when both were administered in addition to standard of care treatment. NOQ19 can be explored as an effective adjunct solution for the management of COVID-19. During pandemics like COVID-19, when there are limited resources at hospitals, an integrated management using NOQ19 provides early recovery which allows rational utilization of limited resources and reduces burden on healthcare systems.

\section{Declarations}

Data Availability: The individual patient level data can be accessed at the following link: https://docs.google.com/spreadsheets/d/1 keaMxG6JblvyGV1n7EMbK8Yo_WaJbAiPeDj_KTHvpiQ/edit\#gid=0

\section{Acknowledgments}

We would like to thank Dr. Ravi Reddy (Chief Science Officer) and Dr Hari Venkatesh (Head, Research \& Development - Healthcare) from Sriveda Sattva for providing NOQ19 and placebo tablets to the study sites AlIMS Jodhpur, AlIMS Rishikesh and SMVMCH. We would like to acknowledge Dr. Somya Ramrakhyani for language edits. We would also like to thank Prateek Harsora for coordinating the study.

\section{Disclosure}

The author reports no conflicts of interest in this work.

\section{Data Availability Statement}

The data that support the findings of this study are available from the corresponding author, Divya Kanchibhotla, upon reasonable request.

\section{Author contributions}

Conceptualization: Divya Kanchibhotla, Pankaj Bhardwaj; Data curation: Pankaj Bhardwaj, Kalaiselvan Ganapathy, Monika Pathania, K H Naveen, Jaykaran Charan, Siddhartha Dutta, Ravisekhar Gadepalli, Srikanth Srinivasan, Manoj Kumar Gupta, Akhil D Goel, Naresh Midha, Bharat Kumar, Meenakshi Sharma, Praveen Sharma, Mithu Banerjee, Prasenjit Mitra, Sanjeev Misra, Vinayagamoorthy V, Girija Subramaniant, Praveen R Puneet Dhamija, Archana Singh; Formal Analysis: Divya Kanchibhotla, Saumya Subramanian; Funding acquisition: Divya Kanchibhotla; Investigation: Pankaj Bhardwaj; Methodology: Divya Kanchibhotla; Project 
administration: Pankaj Bhardwaj; Resources: Kalaiselvan Ganapathy, Monika Pathania; Supervision: Divya Kanchibhotla; Validation: Pankaj Bhardwaj, Kalaiselvan Ganapathy, Monika Pathania, Vartika Saxena, Minakshi Dhar; Visualization: Divya Kanchibhotla; Writing - original draft: Saumya Subramanian; Writing review \& editing: Divya Kanchibhotla, Pankaj Bhardwaj, Monika Pathania

\section{References}

1. World Health Organization. COVID-19 Research. (https://www.who.int/publications/m/ item/covid-19research-and-innovation-achievements) . Accessed on 10th September, 2021

2. Coronavirus (COVID-19) Vaccinations. https://ourworldindata.org/covidvaccinations? country=OWID_WRL. Accessed on 10th September, 2021.

3. Singh R, Goel S, Bourgeade P, et al. Ayurveda Rasayana as antivirals and immunomodulators: potential applications in COVID-19. ESPR. 2021:1-27.

4. Joshi MB, Kamath A, Nair A, et al. Modulation of neutrophil (dys) function by Ayurvedic herbs and its potential influence on SARS-CoV-2 infection. $J$ Ayurveda Integr Med.

5. Malabadi RB, Kolkar P, Meti T, et al. TRADITIONAL HERBAL FOLK MEDICINE USED FOR CONTROLLING CORONA VIRUS (SARS-COV-2) DISEASE (COVID-19). Int j of innov and sci res. ;3(7):1507-17.

6. Malabadi RB, Meti NT, Chalannavar RK. Role of herbal medicine for controlling coronavirus (SARS-CoV-2) disease (COVID-19). International Journal of Research and Scientific Innovations. 2021;8(2):135-65.

7. Subhrajyoti C. Immunomodulatory herbs of Ayurveda and covid-19: a review article. Journal of Ayurveda and Integrated Medical Sciences. 2020;5(02):203-8.

8. Shree P, Mishra P, Selvaraj C, et al. Targeting COVID-19 (SARS-CoV-2) main protease through active phytochemicals of ayurvedic medicinal plants-Withania somnifera (Ashwagandha), Tinospora cordifolia (Giloy) and Ocimum sanctum (Tulsi)-a molecular docking study. J Biomol Struct Dyn. 2020:1-4.

9. Tripathi MK, Singh P, Sharma S, et al. Identification of bioactive molecule from Withania somnifera (Ashwagandha) as SARS-CoV-2 main protease inhibitor. J Biomol Struct Dyn. 2020:1-4.

10. Chopra A, Gautam PC, Tillu G, et al. Randomized, double blind, placebo controlled, clinical trial to study co-administration of Ashwagandha on safety, immunogenicity, and protection with COVID-19 vaccine: A Study Protocol. medRxiv. 2021.

11. Nivetha R, Bhuvaragavan S, Muthu Kumar T, et al. Inhibition of multiple SARS-CoV-2 proteins by an antiviral biomolecule, seselin from Aegle marmelos deciphered using molecular docking analysis. $J$ Biomol Struct Dyn. 2021:1-2.

12. Vetrivel U, Deshpande S, Hegde HV, et al. Phytochemical moieties from Indian traditional medicine for targeting dual hotspots on SARS-CoV-2 spike protein: an integrative in-silico approach. Front Med. 2021;8:545.

13. Qazi S, Das S, Khuntia BK, et al. In Silico Molecular Docking and Molecular Dynamic Simulation Analysis of Phytochemicals From Indian Foods as Potential Inhibitors of SARS-CoV-2 RdRp and 3CLpro. Nat Prod Commun. 2021;16(9):1934578X211031707. 
14. Maurya DK. Evaluation of Yashtimadhu (Glycyrrhiza glabra) active phytochemicals against novel coronavirus (SARS-CoV-2).

15. Vincent S, Arokiyaraj S, Saravanan M, et al. Molecular docking studies on the anti- viral effects of compounds from Kabasura Kudineer on SARS-CoV-2 3CLpro. Front Mol Biosci. 2020;7:434.

16. Rizvi ZA, Tripathy MR, Sharma N, et al. Effect of prophylactic use of intra-nasal oil formulations in the hamster model of Covid-19. bioRxiv

17. Krutika J. Experimental and Clinical Evidence of Andrographis paniculata (Roxb.) Wall. Ex Nees (Bhunimba)-A Review.

18. Sa-Ngiamsuntorn K, Suksatu A, Pewkliang Y, et al. Anti-SARS-CoV-2 activity of Andrographis paniculata extract and its major component Andrographolide in human lung epithelial cells and cytotoxicity evaluation in major organ cell representatives. J Nat Prod. 2021;84(4):1261-70.

19. Hanff TC, Mohareb AM, Giri J, et al. Thrombosis in COVID-19. Am J Hematol. 2020;95(12):1578-89.

20. Kataky A, Handique PJ. A brief overview on Andrographis paniculata (Burm. f) Nees., a high valued medicinal plant: Boon over synthetic drugs. Asian J Sci Technol 2010;6:113-8.

21. Zahedipour F, Hosseini SA, Sathyapalan T, et al. Potential effects of curcumin in the treatment of COVID19 infection. Phytother Res. 2020;34(11):2911-20.

22. Soni VK, Mehta A, Ratre YK, et al. Curcumin, a traditional spice component, can hold the promise against COVID-19?. Eur J Pharmacol. 2020:173551.

23. Kanchibhotla D, Subramanian S, Reddy R, et al. An In-vitro evaluation of a polyherbal formulation, against SARS-CoV-2, Researchsquare. 2021. https://doi.org/ 10.21203/rs.3.rs-936472/v1

24. Kanchibhotla D, Subramanian S, KR HV. To study the in-vivo efficacy and safety of AYUSH polyherbal formulation among COVID-19 infected Syrian gold hamsters. Researchsquare, 2021. https://doi.org/10.21203/rs.3.rs-936462/v1

25. Kanchibhotla D, Harsora P, Subramanian S, Venkatesh H. Efficacy of a polyherbal formulation in the treatment of SARS CoV-2 disease: An open labelled feasibility study. Researchsquare, 2021. https://doi.org/10.21203/rs.3.rs-923003/v1

26. NATIONAL CLINICAL MANAGEMENT PROTOCOL COVID-19. https:// w w w . m o h f w . g o v . i n / p d f / UpdatedDetailedClinicalManagementProtocolforCOVID19adultsdated24052021.pdf. Accessed on $30 / 09 / 2021$

27. Revised Guidelines on Clinical Management of COVID-19. https://mohfw.gov.in/ pdf/RevisedNationalClinicalManagementGuidelineforCOVID1931032020.pdf. Acessed on 30/09/2021

28. Israel GD. Determining sample size.1992: 1-5

29. Kumar G, Mukherjee A, Sharma RK, et al. Clinical profile of hospitalized COVID-19 patients in first and second wave of the pandemic: insights from an Indian registry based observational study. Indian $\mathrm{J} M e d$ Res. 20218:Epub-ahead.

30. Bajpai N, Wadhwa M. COVID-19 in India: Disease Burden, Managing the second wave and Innovations.

31. Bogam P, Joshi A, Nagarkar S, et al. The burden of COVID-19 and Case Fatality Rate in Pune India: An Analysis of First and Second Wave of the Pandemic. medRxiv 
32. Singh R, Goel S, Bourgeade P, et al. Ayurveda Rasayana as antivirals and immunomodulators: potential applications in COVID-19. 2021:1-27.

33. Hoever G, Baltina L, Michaelis M, et al. Antiviral activity of glycyrrhizic acid derivatives against SARScoronavirus. J Med Chem. 2005;48(4):1256-9.

34. Anagha K, Manasi D, Priya L et al. Scope of Glycyrrhiza glabra (Yashtimadhu) as an antiviral agent: a review. Int J Curr Microbio. Ap. Sci. 2014;3(12):657-65.

35. Cinatl J, Morgenstern B, Bauer G, et al. Glycyrrhizin, an active component of liquorice roots, and replication of SARS-associated coronavirus. Lancet 2003;361(9374):2045-6.

36. Gheware A, Panda L, Khanna K, et al. Adhatoda vasica rescues the hypoxia-dependent severe asthma symptoms and mitochondrial dysfunction. J. Physiol. Lung Cell Mol. Physiol. 2021;320(5):L757-69.

37. Gupta A, Prajapati PK. A clinical review of different formulations of Vasa (Adhatoda vasica) on Tamaka Shwasa (asthma). 2010;31:520-524.

38. Singh R, Goel S, Bourgeade P, et al. Ayurveda Rasayana as antivirals and immunomodulators: potential applications in COVID-19. EPSR. 2021:1-27.

39. Wanjarkhedkar P, Sarade G, Purandare B, et al. A prospective clinical study of an Ayurveda regimen in COVID 19 patients. J Ayurveda Integr Med. 2020.

40. Willcox ML, Bodeker G. Traditional herbal medicines for malaria. Bmj. 2004;329(7475):1156-9.

41. Ram TS, Munikumar M, Raju VN, et al. In silico evaluation of the compounds of the ayurvedic drug, AYUSH-64, for the action against the SARS-CoV-2 main protease. J Ayurveda Integr Med. 2021.

42. Patwardhan B, Sarwal R. Significance of AYUSH: India's first line of defence against COVID-19. J Ayurveda Integr Med. 2021;12(2):227.

43. Kotecha R. The journey with COVID-19: initiatives by Ministry of AYUSH. J Ayurveda Integr Med. 2021;12(1):1-3.

\section{Figures}




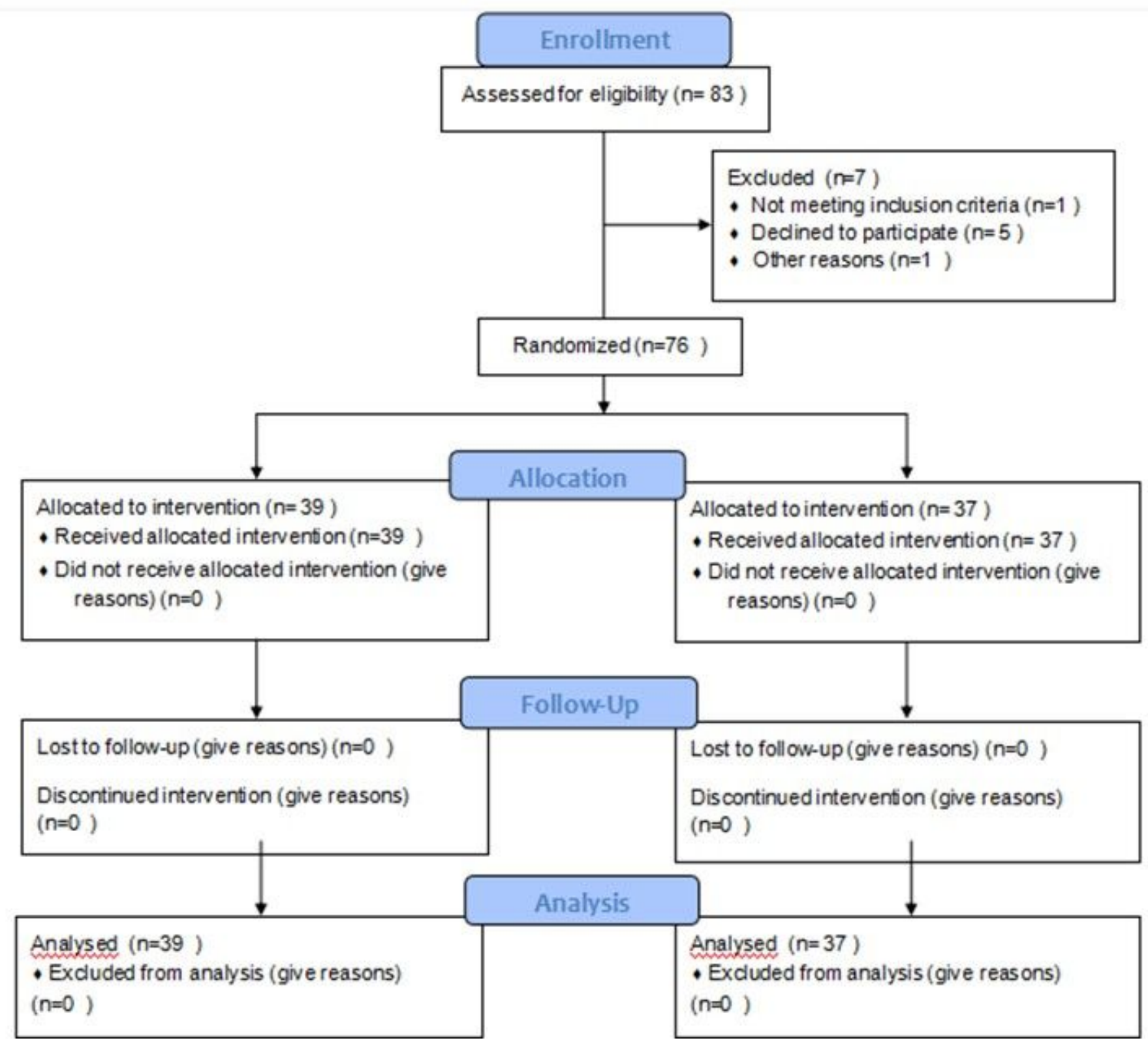

Figure 1

CONSORT Flow Diagram 